\title{
LA MOSCA EN EL CRISTAL: METÁFORAS PARA EL ANIMAL HAMBRIENTO EN HANS BLUMENBERG
}

\author{
THE FLY ON THE GLASS: METAPHORS \\ FOR THE HUNGRY ANIMAL IN HANS BLUMENBERG
}

\section{Iván DE LOS RÍOS GUTIÉRREZ}

Universidad Autónoma de Madrid

\begin{abstract}
Resumen: De acuerdo con Hans Blumenberg, la historia del pensamiento occidental es la historia de los múltiples esfuerzos del hombre por ponerse a salvo del "absolutismo de la realidad". El presente trabajo tiene por objetivo ubicar la propuesta metaforológica de Blumenberg en el marco del filosofar histórico reivindicado por Nietzsche al comienzo de Humano, demasiado humano y el naturalismo filosófico no reduccionista de J. M. Schaeffer en El fin de la excepción humana. La metáfora absoluta de Blumenberg es interpretada, entonces, desde historia natural de un animal inteligente y perplejo caracterizado por lógica de la fantasía, la potencia fabuladora del lenguaje y el pensamiento abstracto.

Palabras clave: Hans Blumenberg, metáfora, condición humana, filosofar histórico, naturalismo.

Abstract: According to Hans Blumenberg, the history of western thought is the history of the multiple human efforts to take shelter in confrontation with the "absolutism of reality". This papers aims to locate Blumenberg's metaphorology within the frame of the "historical philosophyzing" supported by Nietzsche at the beginning of Human, all too human and the philosophical and nonreductionist naturalism supported by J. M. Schaeffer in The end of human exception. Blumenberg's absolute metaphor is interpretated from the perspective of the natural history of an inteligent and perplexed animal characterized by the logic of phantasy, the poetic capacity of language and abstract thinking.
\end{abstract}

Keywords: Hans Blumenberg, metaphor, human condition, historical philosophyzing, naturalism. 
¿Qué quimera es, pues, el hombre? ¿Qué novedad, qué monstruo, qué caos, qué sujeto de contradicciones, qué prodigio? Juez de todas las cosas, imbécil gusano de tierra, depósito de lo verdadero, cloaca de incertidumbre y error, gloria y desecho del universo.

B. Pascal

¿Cuál es tu objetivo en filosofía? - Mostrarle a la mosca la salida de la botella".

L. Wittgenstein

1

Entre los muchos ensayos de definición que jalonan la historia de Occidente y su derivas, pocos tan destacables como esta sutil bravuconada de Georg Simmel: "El ser humano es la criatura hambrienta por excelencia" (Simmel, 1923, p.73, trad. nuestra). Más que un animal racional, un bípedo implume o un saco lúcido de sangre y huesos; más que un zoon politikon, un magnum miraculum o un híbrido de bestia y ángel, el ser humano es un animal famélico, ansioso y moribundo. Un muerto de hambre, literalmente, que cede a un deseo insaciable cuya satisfacción supera los límites del bienestar orgánico en la misteriosa dirección del símbolo. La frase original no tiene desperdicio: "Der Mensch ist das hungrige Wesen schlechthin. Das Tier ist satt wenn es gegessen hat" (El ser humano es la criatura hambrienta por excelencia. El animal queda satisfecho después de comer). ¿Cuál es la dirección propiamente humana del hambre? ¿En qué consisten su destino y su objeto, diferidos hasta el punto de que no parece existir criatura más hambrienta que el hombre? "Schlechthin", dice Simmel: por antonomasia, sin más, por excelencia. Un animal cuyo apetito permanece abierto incluso (y sobre todo) en la saciedad, la saturación y el hartazgo. Las preguntas kantianas de la Crítica de la Razón Práctica se atropellan peligrosamente: ¿Qué puedo conocer? ¿Qué debo hacer? ¿Qué me cabe esperar? Y, ante todo: ¿qué es el hombre? ¿Por qué esta hambre voraz? ¿Hacia dónde se dirige este ejército de bocas hambrientas? ¿Y hambrientas de qué? ¿De poder? ¿De saber? ¿De gloria? ¿Hambrientas de Dios, amor, eternidad, sentido? ¿Un orificio insaciable que solo quiere seguir queriendo o una mueca atravesada en el rostro que pide paz, serenidad y consuelo? Quizá esta definición quede huérfana sin aquella otra del propio Simmel que Blumenberg recoge en su monumental Descripción del ser humano: "Der Mensch ist ein Trostsuchendes Wesen" (Simmel, 1923, p. 17; citado en Blumenberg, 2010, p. 466). El hombre es (y seguirá siendo) una criatura en busca de consuelo. Eso es todo lo que somos. Todo lo que nos resta: un animal metafísico que oscila entre la conciencia de su propia muerte y los territorios aparentemente firmes de la ciencia, la teología, la filosofía y la creación poética. Nomenclaturas todas para un mismo desconcierto:

En algún rincón, un vestigio del reino olvidado. En alguna muerte violenta, el castigo por haberse acordado del reino. En alguna risa, en alguna lágrima, la sobrevivencia del reino...Se puede matar todo menos la nostalgia del reino, la llevamos en el color de los ojos, en cada amor, en todo lo que profundamente atormenta y desata y engaña. Wishful thinking, quizá; pero ésa es otra definición posible del bípedo implume" (Cortázar, 2013, Rayuela, cap. 71, p. 407). 
2. En los complementos al libro I de El Mundo como Voluntad y Representación, Schopenhauer afirma que el ser humano es el único animal con capacidad de asombro y que dicha potencia (fascinante, sutil y alucinada) nos convierte en organismos metafísicos:

Con excepción del hombre, ningún ser se asombra de su propia existencia, sino que para todos esta se entiende por sí misma, hasta tal punto que ni la notan. En la tranquila mirada de los animales habla todavía la sabiduría de la naturaleza, porque en ellos la voluntad y el intelecto no se han separado aún lo suficiente como para que al encontrarse juntos puedan asombrarse uno de otro (...) Solo después la esencia íntima de la naturaleza (la voluntad de vivir en su objetivación) ha ascendido vigorosa y alegremente a través de los dos reinos de los seres inconscientes y luego por la larga y amplia serie de los animales, llegando finalmente, con la aparición de la razón en el hombre, a la reflexión: entonces se asombra de sus propias obras y se pregunta qué es ella misma. Mas su asombro es tanto más grave por cuanto que aquí, por vez primera, se enfrenta conscientemente a la muerte y, junto a la finitud de toda existencia, le acosa también en mayor medida la vanidad de todo esfuerzo. Con esta reflexión y este asombro nace la necesidad de una metafísica, propia solo del hombre: por eso es un animal metaphysicum (Schopenhauer, 2013, p. 198).

El fragmento de Schopenhauer resuena en un pasaje arrinconado de Platón donde el joven Teeteto se reconoce próximo al desmayo ante los argumentos de Sócrates:

TEET.- Por los dioses, Sócrates, mi admiración es desmesurada (hyperphuos hos thaumadso), cuando me pongo a considerar en qué consiste realmente todo esto. Algunas veces, al pensar en ello, llego verdaderamente a sentir vértigo (skotodinio).

SÓC.- Querido amigo, parece que Teodoro no se ha equivocado al juzgar tu condición natural, pues experimentar eso que llamamos la admiración es muy característico del filósofo (mala gar philosophou touto to pathos, to thaumadsein). Este y no otro es, efectivamente, el origen de la filosofía (arche philosophias)" (Platón, 1998, 155c1-d5).

Aristóteles, por su parte, rendirá homenaje al maestro con una de las frases más célebres de la historia de la metafísica. Un texto donde el asombro y el terror, la perplejidad y la maravilla se enlazan en una trenza originaria que acompaña y precede a la aventura filosófica de Occidente: "Pues los hombres comienzan y comenzaron siempre a filosofar movidos por la admiración (dia gar to thaumadsein)" (Aristóteles, 1998, 982b, 12-13)

Kai nun kai to proton, dice Aristóteles. Tanto ahora como entonces. Ayer, hoy y siempre, los seres humanos comienzan a filosofar movidos por la ignorancia de las causas que dinamizan el horizonte de sentido en que están inmersos. Niños absortos frente a un teatro de marionetas, la ignorancia de las causas genera en el animal humano un particular estado de desconcierto, sorpresa y amenaza: un pavor cerval ante la maravilla de lo que no comprende. No obstante, el pavor mengua con el avance progresivo del conocimiento de aquellos procesos cuyo origen, sentido y finalidad se nos velaban en un comienzo. Como el niño, en efecto, el ser humano aprende a leer, aprende a mirar y a descifrar un texto que alguna vez fue impenetrable: el enigma de una naturaleza cruda, caprichosa y hostil que se va plegando paulatinamente al dominio de los conceptos y las conexiones causales. El misterio que atenaza al ser humano en un estado pre-científico y pre-filosófico concede a la naturaleza el sesgo de un poder indómito, pero va cediendo históricamente su lugar al imperio epistémico de un animal que, mediante el razonamiento y la palabra, debilita, comprende y gobierna todo cuanto le 
rodea. El asombro es el origen de la filosofía por cuanto acompaña el camino del saber humano en sus senderos de victoria y de fuga, en sus transiciones desde la oscuridad hacia la luz y en sus traslados desde la ignorancia y la enfermedad hasta el conocimiento y la salud: la superación kantiana de la infancia en pos de esa madurez ilustrada que, como un estandarte, porta quien tiene el valor de servirse de la propia razón sin la tutela de otro. Ascensión y Anábasis, en definitiva, que describen la distancia que separa la servidumbre de la soberanía y en cuya extensión emerge, poderosa, la vieja Filosofía.

Desde este punto de vista, el asombro, el miedo y la precariedad del sujeto frente al mundo serían la condición de posibilidad de todo empoderamiento epistémico y pragmático del hombre sobre los mecanismos ocultos de la physis. La filosofía, entonces, desde su mismo origen, aparece a nuestros ojos como un ejercicio de abandono: el mecanismo de inteligibilidad que, con la ayuda del método científico y la razón, permite al más extraviado (y hambriento) de los animales no solo alcanzar cierto grado de orientación en el pensamiento y en la acción, sino convertirse, incluso, en el arconte de los principios (archai) y causas últimas de todas las cosas. El enfoque griego del asombro parece satisfacer la demanda del sentido y el hambre voraz con el que hemos abierto estas páginas. La criatura famélica es, por supuesto, un animal sofisticado que aspira a algo más que a la saciedad del puerco. Pero esa aspiración abreva, precisamente, en la conciencia trágica y lúcida de su íntima condición precaria. El ser humano toma conciencia de sí mismo y, al hacerlo, deja para siempre atrás "la mirada tranquila de los animales" de la que habla Schopenhauer. La reflexión es el origen de la inquietud como forma misma de la autoconciencia y como estructura de la existencia. Y es en dicha inquietud, en la mirada ansiosa, perturbada y vehemente del animal metafísico donde se cifra la auténtica clave del asombro como origen de la filosofía que, a juicio de Schopenhauer, Aristóteles ha pasado por alto. Y es que el asombro aristotélico, como sugiere Rosset (2005, pp. 61-70) no es más que un asombro regional, parcelado y, puramente científico: un niño asustado ante un juguete de metal que se mueve misteriosamente. La maravilla queda encerrada en el perímetro de la excepción o suspensión del flujo causal, en el desconocimiento de las razones que operan en la trastienda de los fenómenos. Aristóteles parece identificar el asombro con la percepción de una cierta ausencia de causación y, con ello, la filosofía con el progresivo esclarecimiento de la estructura causal que atraviesa toda región de sentido:

Más es preciso, en cierto modo, que su adquisición [la de la ciencia buscada] se convierta para nosotros en lo contrario de las indagaciones iniciales. Pues todos comienzan, según hemos dicho, admirándose de que las cosas sean así, como les sucede con los autómatas de los ilusionistas [a los que no han visto la causa], o con los solsticios o con la inconmensurabilidad de la diagonal (pues a todos les arece admirable que algo no sea medido por la unidad mínima). Pero es preciso terminar en lo contrario y mejor, según el proverbio, como sucede en los casos mencionados, después de que se ha aprendido: pues de nada se admiraría tanto un geómetra como de que la diagonal llegara a ser conmensurable (Aristóteles, 1998, 983ª10-983b20)

Ahora bien, lo asombroso y estremecedor, lo maravilloso y verdaderamente horrible no es la ausencia de causalidad, sino su presencia omnímoda y, a la vez, inexplicable. La sospecha del absurdo burlón que subyace a toda forma de certidumbre. El animal metafísico no tiembla de pavor ante el mundo porque desconozca los nódulos causales de sus diversas regiones. Todo lo contrario: la fascinación insoportable del sentido estriba en la captación simultánea de, por un lado, la 
omnipresencia de la causalidad en el orden de la experiencia empírica, y, por el otro, su total ausencia de fundamentación. En otras palabras, el ser humano es un animal metafísico porque siendo capaz de comprender el mundo circundante a través del dispositivo etiológico en sus diversos niveles (lógico, empírico, matemático y moral) no consigue captar el porqué del hecho mismo de la experiencia, el sentido mismo de que haya mundo, que seamos conscientes de nuestra presencia en su interior y que hayamos de abandonarlo ineluctablemente tras el zarpazo de la muerte: "Mas su asombro es tanto más grave por cuanto que aquí, por vez primera, se enfrenta conscientemente a la muerte y, junto a la finitud de toda existencia, le acosa también en mayor medida la vanidad de todo esfuerzo" (Schopenhauer, 2013, p. 198).

Ese y no otro es el origen del auténtico filosofar. Ese misterium tremendum et fascinans que nos impone la primacía insuperable de un universo que nos ignora. El mundo aparece, entonces, como lo otro del conocimiento, lo otro del hombre, lo que resta más allá de toda cuantificación y todo proceso de reducción epistémica. El mundo, en fin, como la amenaza constante de un universo que "no tiene ni fundamento ni propósito y se comporta de manera despiadada, indiferente y sin miramientos frente a los intereses de supervivencia y de sentido de los hombres" (Wetz, 1996, p. 78).

Para referirse a la indiferencia cruda de lo real, Schopenhauer hablará de una pulsión ciega y vampírica que aglutina todos los procesos conscientes e inconscientes: Wille. Desde una misma exigencia de radicalidad, en pleno siglo XX y sin miedo a caer en la supuesta ingenuidad de las viejas preguntas fundacionales, Hans Blumenberg prefiere hablar del "absolutismo de la realidad":

\footnotetext{
Si desviamos la mirada de los horrores de la actualidad, pintados con primor profesional o incluso profesoral, y de todos los que traiga el futuro, volviéndola a los de un pasado no tan lejano y a los del primitivo, nos topamos con la necesidad de figurarnos un estadio inicial que cumpla con las exigencias de aquel status naturalis de las teorías filosóficas de la cultura y del Estado. Este concepto límite de extrapolación de características históricas tangibles hacia lo arcaico lo podemos fijar, formalmente, sirviéndonos de una sola determinación: la del absolutismo de la realidad. Lo cual significa que el ser humano no tenía en su mano ni mucho menos las condiciones determinantes de su existencia -y, lo que es más importante, no creía tenerlas en su mano" (Blumenberg, 2003a, p. 11).
}

3. Franz J. Wetz ha definido con maestría el nervio que subyace al proyecto integral de Blumenberg: "La historia del pensamiento occidental es la historia de los múltiples esfuerzos del hombre por ponerse a salvo del absolutismo de la realidad" (Wetz, 1996, p. 79). Emboscarse, urdir, buscar refugio. La propuesta es fascinante y, en muchos sentidos, revolucionaria, por cuanto la clave de acceso al devenir del pensamiento Occidental y a la pregunta por la condición humana van ligadas a un enfoque antropológico en cuyo marco es posible reflexionar sobre las relaciones entre filosofía, metáfora y ficción sin caer en las redes del anti-mimetismo, la teología o la metafísica. Es más: si aceptamos la tesis de Wetz, no parece haber otro modo de abordar los problemas relativos a la condición simbólica del ser humano sin caer en el delirio de grandeza propio del animal racional. Una condición que, como recuerda Pérez de Tudela en su introducción los Paradigmas para una metaforología de Blumenberg, constituye la tarea pendiente del pensamiento crítico por cuanto supone explorar " $<<$ ese tipo de exposición indirecta, según una analogía >> que permite referirse a objetos a los que acaso nunca pueda 
corresponder una intuición” (Pérez de Tudela en Blumenberg, 2003b, p. 23). En efecto, toda forma de expresión cultural abreva en la necesidad antropológica de elaborar estrategias de distanciamiento que permitan al animal autoconsciente eludir el absolutismo de la realidad mediante el hallazgo de esa covacha, ese antro o caverna que, desde antiguo y con diversos rostros, sigue ofreciéndonos resguardo:

Al contrario de Adorno/Horkheimer y Heidegger, que, no obstante las divergencias existentes entre ellos, coinciden en explicar la historia del pensamiento como una transición progresiva del mito al logos explicada en el sentido de una historia del enseñoreamiento del universo - de la razón instrumental y de la supremacía olvidada del Ser por parte del ente-, Blumenberg describe la historia del pensamiento Occidental como historia de los esfuerzos por hacer frente con éxito al universo (Wetz, 1996, p. 80).

Lo que pone en marcha la filosofía occidental, entendida como una estrategia de interpretación y comprensión de la totalidad de lo que existe, no es la natural tendencia del anthropos a la sabiduría ${ }^{1}$ ni la voluntad de dominación sobre todo cuanto "nos es extraño, nos supera en poder y no está a nuestra disposición", como en el caso de Adorno, Horkheimer o Heidegger:

Blumenberg, por el contrario, sitúa en la base de todas las interpretaciones y explicaciones del cosmos un empeño radical en mantenerse a distancia del ser que nos es extraño, nos supera en poder y no está a nuestra disposición. Esta confrontación pone de manifiesto con toda claridad el auténtico pensamiento fundamental de Blumenberg...: por un lado, el absolutismo de la realidad, la terrorífica prepotencia del universo y la incomprensibilidad del cosmos mudo e insondable; por otro, las distintas medidas para domesticar y distanciarse de esta poderosa y muda realidad (Wetz, ibid., cursivas nuestras).

El proyecto blumenberguiano persigue, por tanto, los diferentes modos en que el ser humano ha intentado dotar de significación el páramo de la existencia en su más radical indiferencia y crudeza. ¿Cuáles son las modalidades que ofrecen al animal hambriento vías de escape hacia la significatividad? De acuerdo con Rivera (2010, p. 146), "Blumenberg se ha interesado por tres formas de hacer significativa la realidad (mitología, retórica, metaforología), que en principio han sido consideradas marginales a la filosofía, pero que, en su opinión, acaban siendo también decisivas para la historia de la filosofía". Por cuestiones de espacio, en este trabajo prestamos mayor atención al universo de la metáfora y al proyecto metaforológico de Blumenberg. En todo caso, merece la pena recordar que tanto desde el punto de vista de la metaforología, como de la retórica y la mitología, el programa de Blumenberg se caracteriza principalmente por asumir dos rasgos aparentemente nimios pero absolutamente cruciales en el ejercicio de un nuevo filosofar. Dos rasgos que Nietzsche, al comienzo de Humano, demasiado humano, ya reconoce como propios de una nueva metodología científica apartada de los amores románticos de juventud y de toda metafísica de artistas:

Defecto hereditario de los filósofos: Todos los filósofos comparten el defecto en sí de partir del hombre actual y creer que con un análisis del mismo pueden llegar al objetivo. Sin quererlo, el <<hombre〉> flota ante su mente como una "aeterna veritas", como algo que permanece igual en toda la vorágine, como una medida segura de las cosas. Pero todo lo que el filósofo formula sobre el hombre no es en el fondo más que el testimonio sobre el hombre de un espacio de tiempo muy limitado. La falta de sentido histórico es el defecto originario de todos los filósofos; muchos incluso toman sin pensarlo la configuración más reciente, tal como ha surgido bajo la presión de determinadas religiones, incluso de determinados eventos políticos,

\footnotetext{
${ }^{1}$ Pantes anthropoi tou eidenai oregontai physei. Así reza la frase inicial de la Metafísica de Aristóteles según la cual todos los seres humanos tienden naturalmente al saber. El hambre natural del ser humano le conduciría, por tanto, irremediable y esencialmente, en la dirección del conocimiento puro y desinteresado.
} 
como la forma fija de la que hay que partir. No quieren enterarse de que el hombre ha devenido (...) Pero todo ha devenido. No hay hechos eternos; así como no hay verdades absolutas -Por eso es necesario de ahora en adelante el filosofar histórico, con él, la virtud de la modestia. (Nietzsche, 2014, p. 76, cursivas nuestras).

La modestia y el sentido histórico reivindicados por Nietzsche forman parte de una lectura naturalista del pensador alemán que autores como Brian Leiter llevan años reivindicando: "Nietzsche belongs not in the Company of posmodernists like Foucault and Derrida, but rather in the company of naturalists like Hume or Freud -that is, among, broadly speaking, philosophers of nature" (Leiter, 2002, pp. 2-3). Frente a la apropiación posmoderna del filólogo alemán en sede continental, Leiter percibe en Nietzsche (al igual que en Hume, Marx y Freud) un naturalismo metodológico de extraordinario rendimiento teórico, ético y político que, en sus presupuestos fundamentales, demanda una continuidad elemental entre las investigaciones filosóficas y los resultados de las ciencias de la naturaleza en los últimos siglos de nuestra era. En este sentido, Blumenberg podría ser leído no solo en la línea del naturalismo metodológico de Nietzsche inaugurado en Humano, demasiado humano, sino también en conexión con enfoques teóricos integrales muy sugerentes como el J. M. Schaeffer (2009) en El fin de la excepción humana. De acuerdo con Schaeffer, la tesis de la excepción humana describe una "imagen" que el ser humano se ha dado a sí mismo durante siglos y que, aún hoy, está a la base de todas las formas de segregacionismo y esencialismo. Dicha tesis se sostiene sobre cuatro pilares básicos:

i) En primer lugar, la "ruptura óntica" en el orden de lo viviente entre los animales humanos y el resto de las criaturas vivas:

[...] la Tesis sostiene...que la singularidad del ser humano reside en el hecho de que en su mismo ser es irreductible a la vida animal como tal. En este sentido, ella implica un postulado de ruptura óntica, es decir, una separación radical entre los seres humanos y otras formas de vida (Schaeffer, 2009, p. 23).

ii) En segundo lugar, y partiendo de la ruptura óntica, la tesis implica una peculiar interpretación del clásico dualismo ontológico según el cual existen dos planos de realidad, el espíritu y la materia, cuya relación asume la forma de una dicotomía axiológica y una relación gubernamental:

Por otro lado, por lo que respecta al ser humano mismo, el dualismo ontológico que supuestamente lo caracteriza se ve interpretado como una replicación de la ruptura óntica, que esta vez atraviesa al propio hombre. La tesis de la ruptura óntica no solo opone dos campos de lo viviente, el de lo humano y el de la animalidad, sino que refuerza esta dualidad en el interior de la concepción del propio hombre, a través de múltiples pares oposicionales -cuerpo / alma, racionalidad / afectividad, necesidad / libertad, naturaleza / cultura, instinto/moralidad, etc.- todos los cuales de algún modo oponen al hombre a sí mismo. Aún más que la ruptura óntica entre el ser humano y el mundo animal, es esta ruptura interna al propio ser humano lo que pesó sin duda sobre la imagen que nos hacemos de nosotros mismos" (Schaffer, 2009, p. 25, cursivas nuestras). 
iii) Desde esta figuración bélica que parece oponernos con nosotros mismos, la tesis debe enfatizar como su tercer pilar lo que Schaeffer denomina "gnoseocentrismo" o concepción gnoseocéntrica del ser humano, que "afirma que lo que hay de propiamente -y exclusivamente- humano en el hombre es el conocimiento (según los casos, conocimiento epistémico o conocimiento ético)" (Schaeffer, ibídem). Un gnoseocentrismo que puede asumir la forma teológica del ejemplarismo y la convicción de que "solo la criatura humana puede conocer a su creador" (aunque de forma deficiente en virtud de la ruptura óntica entre lo divino y lo humano) o la modalidad científico-filosófica del cogito cartesiano "concebido como fundamento absolutamente cierto" (ibid.)

iv) Schaeffer concluye la exposición de los presupuestos con una cuarta afirmación fundamental: de acuerdo con la Tesis de la excepción humana,

[...] el conocimiento de lo que es propiamente humano en el hombre exige una vía de acceso y un tipo de conocimiento que se distinguen radicalmente de los medios cognitivos que nos permiten conocer a los otros seres vivientes y a la naturaleza inanimada (ibid.).

Se trata, en efecto, de un "ideal cognitivo antinaturalista" que se opone directamente al naturalismo metodológico, a la virtud de la modestia y al filosofar histórico que Leiter reconocía en autores como Nietzsche, Hume, Marx o Freud. El propio Schaeffer delimita con claridad en qué sentido debe (y no debe) comprenderse su propuesta de interpretación naturalista como una propuesta no reduccionista de la condición humana (i.e., ni fisicalista ni biologicista) próxima a la de John Searle: el naturalismo

[...] es un principio mesocognitivo que guía el estudio de la cuestión de la identidad humana fijándolo en la evolución de las formas de vida biológica en la Tierra. El naturalismo así comprendido, pues, equivale a sostener que el estudio del hombre no puede ser sino el estudio de una forma de vida biológica. De esto se desprende una coerción epistémica mínima para toda atribución de una propiedad al hombre: debe ser compatible con el hecho de que el ser a quien se concede esta propiedad es un ser biológico. Es naturalista todo estudio del hombre compatible con esta coerción".

Si asumimos la coerción epistémica enfatizada por Nietzsche, Leiter y Schaeffer y asumida por Blumenberg (2010, pp. 357-411), podemos retornar a las preguntas elementales que abrían nuestro escrito ¿Cuál es la dirección propiamente humana del hambre? ¿Cómo responder a la pregunta por el anhelo de trascendencia “desde la perspectiva de la retirada de las grandes expectativas" (Blumenberg, 2003b, p. 9), el naturalismo no reduccionista, la muerte de Dios o el nihilismo europeo? ¿Cómo abordar las preguntas fundacionales por la totalidad del mundo y el cómo del buen vivir desde la asimilación lúcida del ser humano como un ser biológico y, por tanto, desde el rechazo de toda interpretación antropológica articulada en torno a la ruptura óntica, el dualismo ontológico, el gnoseocentrismo, el anti-naturalismo o el egipticismo propio de la tradición onto-teológica de Occidente? Se comprende ahora mejor en qué sentido Blumenberg puede ser leído desde el naturalismo metodológico de 
Nietzsche y la necesidad de historizar las relaciones simbólicas del hombre con lo otro de sí. Su trayectoria describe una aproximación a la pregunta antropológica por excelencia que asume el lugar del hombre en el interior de la historia natural del universo y trata de comprender sus grandes constructos conceptuales y culturales desde un doble imperativo: nuestra precariedad constitutiva y la necesidad compensatoria (como diría Odo Marquard) de encontrar estrategias de distanciamiento y remanso frente a la inminencia de una realidad que, desde antiguo y para siempre, amenaza con aniquilarnos

¿Qué función cumplen las metáforas en esta cartografía del miedo, el hambre, el símbolo y el anhelo? En palabras del propio Blumenberg: “¿bajo qué presupuestos pueden tener legitimidad las metáforas en el lenguaje filosófico?” (Blumenberg, 2003b, p. 44).

4. La modestia del filósofo comienza con un exabrupto:

En algún apartado rincón del universo centelleante, desparramado en innumerables sistemas solares, hubo una vez un astro en el que animales inteligentes inventaron el conocimiento. Fue el minuto más altanero y falaz de la "Historia Universal": pero, a fin de cuentas, fue sólo un minuto. Tras breves respiraciones de la naturaleza, el astro se heló y los animales inteligentes hubieron de perecer. Alguien podría inventar una fábula semejante pero, con todo, no habría ilustrado suficientemente cuán lastimoso, cuán sombrío y caduco, cuán estéril y arbitrario es el estado en el que se presenta el intelecto humano dentro de la naturaleza. Hubo eternidades en las que no existía; cuando de nuevo se acabe todo para él no habrá sucedido nada, puesto que para ese intelecto no hay ninguna misión ulterior que conduzca más allá de la vida humana. No es sino humano, y solamente su poseedor y creador lo toma tan patéticamente como si en él girasen los goznes del mundo (Nietzsche, 1996, p. 17).

O tal vez comience con las memorias de un novelista ruso y pascaliano:

La cuna se balancea sobre un abismo, y el sentido común nos dice que nuestra existencia no es más que una breve rendija de luz entre dos eternidades de tinieblas. Aunque ambas son gemelas idénticas, el hombre, por lo general, contempla el abismo prenatal con más calma que aquel otro hacia el que se dirige (a unas cuatro mil quinientas pulsaciones por hora) (Nabokov, 1994, p. 19).

En cualquiera de los dos casos, el minuto más altanero y falaz de la historia universal no puede situarse más que en ese fogonazo hermoso y banal del que habla Nabokov al comienzo de sus memorias. El escritor equipara las dos eternidades sombrías que orillan el balancín de la vida humana. Sin embargo, añade, nos asomamos al abismo prenatal con más calma que al piélago de una muerte futura hacia la que nos dirigimos a mil quinientas pulsaciones por hora. El ritmo frenético de ese "animal descenditivo" cuya naturaleza, a juicio de Giorgio Manganelli, queda descrita en el perímetro de los "verba descendendi". Lo propio del ser humano no es ascender a las cumbres de la razón lumínica, sino descender, inclinarse, calar, rebajarse, despeñarse, precipitarse, derrumbarse, aberrarse (Manganelli, 2006 pp. 14-19). Por eso el italiano anima (agustinianamente) al lector a ser fiel a su descenso: "Sé fiel a tu descenso, homo, amigo". Por eso Fitzgerald pudo afirmar que toda historia es la historia de un derrumbe al comienzo del Crack-up: un proceso en demolición.

De acuerdo con la hipótesis de lectura que venimos perfilando, la figura de Blumenberg parece encajar con la voluntad de abismo descrita por Giorgio Manganelli en su Hilarotragoedia. Desde esta 
perspectiva, la tesis de la excepción humana en sus más diversas formas (artísticas, religiosas, teológicas, científicas y filosóficas) no sería más que un ejercicio milenario de negación y resistencia ante la inminencia del desastre: un ensayo siempre fallido de negación de nuestra más íntima naturaleza mediante el embrujo de un intelecto que nos embruja con la cadencia hipnótica de un síntoma, de un esfuerzo patético por negar, sepultar y olvidar la radical contingencia y finitud del ser humano. Frente a esta milenaria resistencia, la filosofía histórica, modesta y naturalista se posiciona en un ángulo de investigación completamente diferente: el ser radicalmente finito habita, resiste y sobrevive en el universo indirecto de la mediación simbólica. Es precisamente allí —en el espacio de la aproximación retórica, indirecta y especular del hombre al mundo - donde comienza y donde ha de regresar la modestia del filósofo, pues "la referencia humana a la realidad es indirecta, ardua, retardada, selectiva y, por encima de todo, metafórica" (Blumenberg citado en Wetz, 1996, p. 13). El espacio vibrátil de la metáfora cuya investigación pormenorizada comienza en 1958 con los Paradigmas para una metaforología y con la impronta de una pregunta por los presupuestos que garantizan la legitimidad de las metáforas en el lenguaje filosófico. Pérez de Tudela enfatiza este aspecto en su ensayo introductorio:

\footnotetext{
El solo planteamiento de la pregunta presupone un ideal filosófico, y también histórico-filosófico, signado por la conciencia metodológica cartesiana (y también husserliana), que hace de la precisión terminológico-conceptual un ideal, $e l$ ideal epistémico, y que en consecuencia niega o rebaja la legitimidad de aquellas formas de lenguaje que, por su carácter impreciso o traslaticio, no alcanzan todavía, o nunca podrán alcanzar, la nitidez intelectual de un contenido mental reducible a fórmula (Pérez de Tudela en Blumenberg, 2003b, p. 22).
}

Desde el ángulo de un ideal cartesiano-husserliano, las metáforas solo pueden ser consideradas como ornamentos, elementos provisionales, confusos y superables en el decurso de la razón hacia el desciframiento (y control) del libro de la naturaleza. En efecto, la metáfora es un recurso subsidiario allí donde el concepto aún no ha conseguido agotar y reducir la complejidad de su objeto. Mejor: allí donde la intuición aún no ha sido plenamente subsumida en el esquema categorial. En tales casos, las metáforas

[...] pueden ser restos, rudimentos en el camino del mito al logos (...) Aquí, la metaforología sería reflexión crítica que ha de descubrir, y transformar en piedra de escándalo, lo impropio del enunciado traslaticio. Sólo que, además - empecemos planteándolo como pura hipótesis - ciertas metáforas pueden ser también elementos básicos del lenguaje filosófico, transferencias que no se pueden reconducir a lo propio, a la logicidad. (Blumenberg, 2003b, p. 44).

Esta "pura hipótesis" de los Paradigmas constituye el primer paso para una reivindicación de la lógica de la fantasía y un replanteamiento "de la relación entre fantasía y lógos", de la compleja intimidad entre el supuesto carácter genuino de un lenguaje literal (que se quiere auténtico y propio) y el pretendido carácter metafórico de un lenguaje figurado (que se por lo general es tachado de impropio). Blumenberg se hace eco de la posición de Vico en relación con el lenguaje metafórico. Un lenguaje que, lejos de pertenecer a la época primitiva de la Historia, entiende la fantasía 
[...] no sólo como sustrato para transformaciones en la esfera de lo conceptual -en donde, por así decirlo, pueda ser elaborado y transformado elemento tras elemento, hasta que ese agote el depósito de las imágenessino como una esfera catalizadora en la que desde luego el mundo conceptual se enriquece de continuo, pero sin por ello modificar y consumir esa reserva fundacional de existencias (Blumenberg, 2003b, p. 45).

La metaforología de Blumenberg se presenta, entonces, como una teoría de las representaciones e imágenes que el ser humano hace respecto de sí mismo (Wetz, 1996, p. 15). Pero también como una superación del desprecio simplificador de esa dimensión simbólica que, a juicio de Ernst Cassirer, delimita y orienta la estructura de la condición humana y el ser mismo del animal symbolicum:

El mito, el arte, el lenguaje y la ciencia aparecen como símbolos [...] fuerzas que crean y establecen, cada una de ellas, su propio mundo significativo [...] son [...] órganos de la realidad, puesto que solo por medio de ellos lo real puede convertirse en objeto de captación intelectual y, como tal, resultar visible para nosotros (Cassirer, 1973, p. 14).

La condición simbólica y traslaticia implicaría que la función cardinal del intelecto humano

[...] no es otra que la de crear significaciones mediante las cuales organizar los objetos del mundo -siguiendo la estela kantiana-. Nuestra prioridad es esquivar lo que nos resulta molesto mediante la oferta de un startingpoint, una imagen coherente y total de la realidad, esto es, un suelo firme (Ros, 2012, p. 209).

El intelecto, como ya afirmara Nietszsche, se impone sobre el entorno negociando, fingiendo, fintando, construyendo modelos de significatividad y habitabilidad que, en ningún caso, se ajustan a una supuesta estructura objetiva, autónoma y extra-predicativa que vendría a ser desvelada con claridad y mesura dentro de los límites del concepto y el lenguaje literal. Es importante insistir, como hace Wetz, en que el interés de Blumenberg por la metaforicidad del lenguaje y por la figura misma de la metáfora no apunta a la supuesta correspondencia entre las imágenes y el mundo, sino a la funcionalidad misma de la figura (Wetz, 1996, p. 15). En este sentido, Wetz distingue tres funciones principales de la metáfora que podemos resumir para ir concluyendo:

i) En primer lugar, una función ornamental que, desde Quintiliano, identifica las metáforas con adornos brillantes, refrescantes y luminosos que, si bien "otorgan un esplendor especial a determinadas exposiciones", a la par que potencian su eficacia, no "contribuyen a ampliar el alcance de sus aserciones" (Wetz, 1996, p. 16). En sí misma, la metáfora es un recurso estilístico ya siempre expresable en clave puramente lógico-conceptual.

ii) En segundo lugar, una función pre-reflexiva de acuerdo con la cual metáfora habita en el orden confuso e impreciso del lenguaje figurativo. Dicho lenguaje vehicularía de modo oscuro e indistinto aquello que la filosofía y la ciencia estarían llamadas a expresar con claridad y distinción. La metáfora no pasaría, entonces, de ser un residuo, un pecio, un rudimento que se sustrae al perímetro siempre bien delimitado de la definición y el concepto. Ese carácter residual y rudimentario convertiría a todo lenguaje figurativo en una 
mera transición provisional a la culminación definitiva del concepto y la definición como modelo de transparencia entre el pensamiento y el mundo:

En ese estado final, el lenguaje filosófico sería, en sentido estricto, puramente "conceptual": todo puede definirse, así que todo tiene también que definirse, ya no queda nada lógicamente provisional, lo mismo que ha desaparecido la morale provisoire [moral provisional]. De ahora en adelante, todas las formas y elementos del modo traslaticio de hablar, en el más amplio sentido, resultarían provisionales y lógicamente superables; su único significado funcional sería el de ser pasos, el espíritu humano se adelantaría en ellos a su consumación responsable... (Blumenberg, 2003b, p. 42).

iii) La tercera función constituye la verdadera apuesta de Blumenberg y se fragua con potencia en los Paradigmas de la mano de una tradición que recorre la línea de Vico, Hamman, Nietzsche y Cassirer, entre otros. Sin duda, las metáforas pueden ser restos, rudimentos, adornos o residuos conceptualizables a medio y largo plazo. Pero lo cierto es que pueden ser mucho más: elementos nucleares del lenguaje filosófico y no superables en el ámbito de la logicidad. Traslados que, por irreductibles al ámbito lógicoconceptual, Blumenberg sugiere denominar "metáforas absolutas" y que operan como imágenes funcionales que “ $<<$ responden $>>$ a preguntas aparentemente ingenuas, incontestables por principio, cuya relevancia radica simplemente en que no son eliminables, porque nosotros no las planteamos, sino que nos las encontramos como ya planteadas en el fondo de la existencia" (Blumenberg, 2003 b, 62). Dichas preguntas ineludibles son, como subraya Wetz, preguntas teóricas referidas a la totalidad y preguntas pragmáticas referidas a la orientación en el mundo, al cómo del vivir en búsqueda de una vida buena. Preguntas, a fin de cuentas, a la altura del comienzo del prólogo a la primera edición la Crítica de la razón pura de Kant, donde el sabio de Königsberg coquetea con la idea de que el ser humano está condenado a perseguir el espejismo de un oasis en mitad del desierto:

La razón humana tiene el destino singular, en uno de sus campos de conocimiento, de hallarse acosada por cuestiones que no puede rechazar por ser planteadas por la misma naturaleza de la razón, pero a las que tampoco puede responder por sobrepasar todas sus facultades (Kant, 1995, p. 7).

Una mosca encerrada en una botella de cristal que, por un instante, ha sucumbido a la ilusión de la salida de la mano del más arrogante de los animales: el ilusionista, el prestidigitador, el filósofo.

5. La propuesta de Hans Blumenberg responde a una concepción antropológica a ras de suelo. Odo Marquard, admirador y amigo del propio Blumenberg y conocido por sus tesis en favor de la una 
apología de la contingencia, llegó a condensar la filosofía de Blumenberg en dos elementos funamentales: la descarga del absoluto y la finitud. La historia del ser humano es la persecución simbólica de los diversos modos en el que ser humano se descarga del absolutismo de la realidad. ¿Pero cómo soltar lastre? ¿Cómo habilitar un espacio de juego en el que saciar el hambre constitutiva de un animal que anhela el sentido en el interior de un universo indiferente que acabará por engullirlo? No lo parece, pero esta pregunta es tan vieja como la fábula de Perseo y Medusa. Una pregunta griega, oriental, arcaica: ¿cómo enfrentar el Caos? ¿Cómo avanzar rodeados de muerte sin quedar petrificados por la mirada frontal de las fuerzas primigenias que nos preceden? Como Perseo, Blumenberg apuesta por el orden de la mediación. El lugar de lo humano en sentido estricto es la superficie especular de un escudo dorado. La teoría de la metáfora de Hans Blumenberg se mueve en la aceptación trágica de la debilidad consustancial al hombre en términos biológicos, pero nos encuentra armados de palabra y de poesía, de creación, de ciencia y de símbolo, de estrategias de construcción de mundos posibles en cuyo interior, aunque sea por un instante, recorrer la longitud angosta de nuestros anhelos y expectativas. La historia de esas imágenes irreductibles que, ayer, hoy y siempre, parecen dar la razón al maestro Borges: "Quizá la historia universal es la historia de unas cuantas metáforas”.

\section{Referencias bibliográficas}

ARISTÓTELES (2018). Metafísica, trad. trilingüe de V. García Yebra. Madrid: Gredos.

Blumenberg, H. (2003a). Trabajo sobre el mito. Barcelona: Paidós.

Blumenberg, H. (2003b). Paradigmas para una metaforología. Madrid: Trotta.

Blumenberg, H. (2010). Descripción del ser humano. Buenos Aires: FCE.

CAssirer, E. (2013). Mito y lenguaje, Buenos Aires: Nueva Visión.

CORTÁzAR, J. (2013). Rayuela. Barcelona: Random Penguin House.

KANT, I. (1995) Crítica de la razón pura. Madrid: Alfaguara.

LEITER, B. (2002). Nietzsche on morality. New York: Routledge.

MANGANELli, G. (2006). Hilarotragoedia. Siruela: Madrid.

NABOKOV, V. (1994). Habla, memoria. Barcelona: Anagrama.

NiETZSCHE, F. (1996). Sobre verdad y mentira en sentido extramoral. Madrid: Tecnos.

NIETZSCHE, F. (2014). Humano, demasiado humano, vol. I, par. 2, Obras completas, vol. III, obras de madurez. Madrid: Tecnos.

Platón (1998). Teeteto, en: Diálogos, vol. V., Gredos, Madrid.

RIVERA GARCíA, A. (2010). Hans Blumenber: mito, metáfora absoluta y filosofía política. INGENIUM. Revista de historia del pensamiento moderno, 4, 145-165.

Ros Velasco, J. (2012). Metaforología y antropología en Hans Blumenberg. Azafea. Revista de Filosofía, 14, 207-231.

Rosset, C. (2005). Escritos sobre Schopenhauer. Valencia: Pre-textos.

SCHAEFFER, J. M. (2009). El fin de la excepción humana. México: FCE. 
SCHOPEnhauer, A. (2013). El mundo como voluntad y representación, vol. II. Complementos. Madrid: Trotta.

Simmel, G. (1923). Fragmente und Aufsätze -aus dem Nachlass und Veröffentlichungen der letzen Jahren, ed. G. Kantorowic. Munich: Drei Masken.

WeTZ, H. J. (1996). Hans Blumenberg. La modernidad y sus metáforas. Valencia: Edicions Alfons el Magnanim. 